ELECTRICAL COMMUNICATIONS 


\section{ELECTRICAL COMMUNICATIONS}

\section{Theory, worked examples and problems}

R. G. MEADOWS 
(C).G.Meadows 1976

All rights reserved. No part of this publication may be reproduced or transmitted, in any form or by any means, without permission.

\author{
First published 1976 by \\ THE MACMILLAN PRESS LTD \\ Iondon and Basingstoke \\ Associated companies in New York Dublin \\ Melbourne Johannesburg and Madras
}

SBN 333181824

ISBN 978-0-333-18182-9 ISBN 978-1-349-02588-6 (eBook)

DOI 10.1007/978-1-349-02588-6

This book is sold subject to the standard conditions of the Net Book Agreement.

This paperback edition is sold subject to the condition that it shall not, by way or trade or otherwise, be lent, re-sold, hired out, or otherwise circulated without the publisher's prior consent in any form of binding or cover other than that in which it is published and without a similar condition including this condition being imposed on the subsequent purchaser. 


\section{CONTENTS}

$\begin{array}{ll}\text { Preface } & \text { XI }\end{array}$

1. SIGNAL ANALYSIS AND SYSTEM RESPONSE 1

1.1 Theory summary 1

1. Introduction 1

2. Fourier Series : Frequency Spectra of Periodic Signals 1

(a) Real form of the Fourier series

(b) Exponential or complex form of the Fourier series

(c) Normalized power of a periodic signal: Parseval's theorem

3. Fourier Transforms: Frequency Spectra of Aperiodic Signals

(a) Development of Fourier transform from Fourier series

(b) Normalized energy of a non-periodic signal: Rayleigh's theorem

4. The Determination of System Response using Fourier Transforms

5. Cross- and Auto-correlation of Signals
(a) Cross-correlation
(b) Auto-correlation

1.2 Worked Problems

1.3 Exercise Problems

2. NOISE

2.1 Theory summary $\quad 25$

$\begin{array}{ll}\text { 1. Thermal Noise } & 25\end{array}$

2. Shot Noise $\quad 25$

3. Available Signal and Noise Powers 25 
4. Available Power Gain and Equivalent Noise Bandwidth

5. Noise Temperatures

(a) Standard ambient temperature, $T_{0}$

(b) Effective noise temperature of a source, $T_{S}$

6. Noise Factor or Figure

7. Noise Factor and Temperature of Cascaded Networks

2.2 Worked Problems

2.3 Exercise Problems

3. AMPLITUDE AND ANGLE MODULATION SYSTEMS

3.1 Theory Summary

1. Amplitude Modulation

(a) Double sideband amplitude modulation

(b) Suppressed carrier and single sideband modulation

2. Angle (Frequency and Phase) Modulation

(a) Frequency and phase modulated waves

(b) Bandwidth of an f.m. wave

3. Frequency Division Multiplexing

3.2 Worked Problems

3.3 Exercise Problems

4. PULSE AND PCM MODULATION 60

4.1 Theory Summary 60

1. Pulse Amplitude and Pulse Time Modulation 60
(a) Pulse amplitude modulation (PAM)
(b) Pulse time modulation (PTM)

2. Sampling and Recovery Theorems
(a) Sampling theorem 1
(b) Sampling theorem 2 
3. Pulse Code Modulation
(a) Quantization
(b) Companding
(c) Coding and decoding

4. Time Division Multiplexing (TDM)

$\begin{array}{lll}4.2 & \text { Worked Problems } & 65\end{array}$

$\begin{array}{lll}4.3 & \text { Exercise Problems } & 73\end{array}$

5. TRANSMISSION LINES AND WIAVEGUIDES $\quad 79$

5.1 Theory Summary $\quad 79$

1. Transmission Line Equations $\quad 79$

2. Steady State Solutions 80

3. Parameters of Terminated Lines 82
(a) Reflection coefficient
(b) Input impedance
(c) Standing waves and voltage standing wave ratio

4. Field Solutions for Coaxial Lines and Waveguides
(a) Coaxial lines
(b) Parallel plate stripline
(c) Rectangular waveguides
(d) Circular waveguides

5.2 Worked Problems

$\begin{array}{lll}5.3 & \text { Exercise Problems } & 99\end{array}$

$\begin{array}{ll}\text { 6. ANTENNAS } & 107\end{array}$

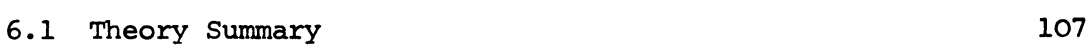

$\begin{array}{ll}\text { 1. Antenna Parameters } & 107\end{array}$

(a) Power gain, G, and directive gain, G 
(b) Radiation pattern

(c) Beam-width and side-lobes

(d) Radiation resistance, $R_{r}$

(e) Effective aperture, $\mathrm{A}_{\mathrm{e}}$

(f) Effective length, $1_{e}$, of a linear antenna

2. Power Density, Radiated and Received Powers

(a) Power density of an electromagnetic wave: Poynting's theorem

(b) The total power radiated by an antenna, $\mathrm{P}_{\mathrm{T}}$

(c) The total power received by an antenna

3. Antenna Arrays

(a) Radiation pattern of an n-element, equally spaced, linear array

(b) Beam steering

4. Aperture Illumination and Far-field Patterns

6.2 Worked Problems

6.3 Exercise Problems

7. SHORT WAVE, MICROWAVE AND RADAR SYSTEMS

7.1 Theory Summary

1. Propagation via the Ionosphere

(a) The system

(b) Refractive index

(c) Critical and maximum useable frequencies for a given ionospheric layer

(d) Maximum range

2. Line of Sight and Microwave Communication Systems

(a) Power transmitted over a free space line-of-sight link 

(b) Interference between direct and reflected waves
(c) Block diagram of a microwave radio link
(d) Signal-to-noise ratio at receiver

3. Radar Systems

(a) Free space radar equation

(b) Block diagram of a pulse radar system

(c) Frequency modulated, continuous wave (f.m. - c.w.) radar

(d) Doppler radar

(e) Measurement of range and velocity using triangular f.m. - c.w. radar

A.1 Trigonometric Identities 173

$\begin{array}{lll}\text { A.2 Fourier Series } & 173\end{array}$

(a) Expansions for some useful functions

(b) Series for signals with symmetry

A.3 Fourier Transforms
(a) Properties
(b) Table of transform pairs

A.4 Table of sinc and Si Functions
(a) Values of $J_{n}(x)$ for $n=0$ to 6
(b) Zeros of $J_{n}(x)$ and $J_{n}{ }^{\prime}(x)$
(c) Series approximations for $J_{n}(x)$ 


\section{PREFACE}

This book has been designed to provide students, who are following courses in Electronics, with summarized theory notes, worked examples and exercise problems in the important field of Electrical Communications.

Each chapter is divided into three basic sections :

1. The first section gives a brief review of the relevant theory and summarizes the important results.

2. The second section contains fully worked examples.

3. The third section consists of problems, to which answers are given at the back of the book.

The contents of the book have been chosen to cover the majority of communications topics normally met by students in University, Diploma, Higher National Certificate or equivalent courses of study. 